\title{
Crescentic Glomerulonephritis in a Sub-Saharan Country: Clinical Presentation, Etiological and Evolutive Profile
}

\author{
Maria Faye, ${ }^{1,}$ Ahmed Tall Lemrabott, ${ }^{1}$ Khodia Fall, ${ }^{1}$ Mohamed Moustapha Cherif Dial, ${ }^{2}$ Mouhamadou \\ Moustapha Cisse, ${ }_{1}^{1}$ Nisrine El Boumaoui, ${ }^{1}$ Moustapha Faye, ${ }^{1}$ Alex Rich Ismael Keita, ${ }^{1}$ Mansour \\ Mbengue, ${ }^{1}$ Kane Yaya, ${ }^{3}$ Abdou Niang, ${ }^{1}$ Boucar Diouf, ${ }^{1}$ and El Hadji Fary Ka ${ }^{1}$ \\ ${ }^{1}$ Nephrology Department Cheikh Anta diop University, Senegal \\ ${ }^{2}$ Anatomo-Pathology Department, Cheikh Anta Diop University, Dakar, Senegal \\ ${ }^{3}$ Nephrology and Internal Medicine Department of Assane Seck University, Senegal \\ "Corresponding author: Maria Faye, Nephrology Department Cheikh Anta diop University, Senegal. E-mail: mariafayemf@gmail.com
}

Received 2017 February 14; Revised 2017 March 22; Accepted 2017 April 04.

\begin{abstract}
Background: Crescentic extra-capillary glomerulonephritis (ECGN) is a diagnostic and therapeutic emergency. In black Africans, little data are available on this lesion. This study aimed at determining the clinical/biological and evolutionary patterns of ECGN and identifying factors of poor prognosis.

Methods: This was a retrospective study conducted over a period of 5 years. All patients with extra-capillary proliferation of $\geq 50 \%$ in Bowman's space upon kidney biopsy were involved. The researchers compared 2 groups of patients: group A (patients, who fully recovered from renal function after 3 months of treatment) and group B (patients developing signs of chronic renal insufficiency) in order to identify factors responsible for a poor renal prognosis.

Results: Forty cases of crescentic glomerulonephritis were found in 750 kidney biopsies, i.e. a prevalence of 5.33\%. The mean age of the patients was $33.9 \pm 16.65$ years, with a gender ratio of 0.53 . Upon admission, $85 \%$ of cases had renal insufficiency, with oligoanuria present in $62.5 \%$. By employing light microscopy, the crescents were found to be cellular in $60 \%$, fibro-cellular in $32.5 \%$, and fibrous in 7.5\%. The etiologies were mainly lupus in $32.5 \%$ of cases, followed by ANCA-related vasculitis in $27.5 \%$ of cases, and infectious causes in $17.5 \%$ of cases. Outside of the infectious context, basic treatment relied on immune suppression combining corticosteroids and cytotoxic drugs. The evolution was marked by transition to a chronic state in $72.7 \%$ of cases; $18.2 \%$ of patients recovered normal renal function. The factors responsible for a poor renal prognosis were oligoanuria $(P=0.0008)$, high creatinine level upon admission $(P$ $=0.0001)$, use of hemodialysis $(\mathrm{P}=0.0001)$, and evidence of fibro-cellular and fibrous crescents $(\mathrm{P}=0.013)$.

Conclusions: Crescentic glomerulonephritis was relatively common in the current patients. The etiology was dominated by lupus in the study's context. This rapidly causes chronic renal failure, hence explaining the interest in early management.
\end{abstract}

Keywords: Crescentic Glomerulonephritis, Rapidly Progressing Glomerulonephritis (RPGN), Kidney Biopsy

\section{Background}

Proliferative extra-capillary glomerulonephritis (EGN) or crescentic glomerulonephritis (CGN) is not a specific disease, yet a histological manifestation of severe glomerular damage. The term "extra-capillary proliferation" is used to designate the cellular and/or fibrous proliferation that occupies the Bowman's space, arising from its capsule. "Extra-capillary" indicates that proliferation occurs outside of the capillary tuft. There is no universal agreement on the percentage of involved glomeruli to diagnose crescentic GN, yet the most commonly used percentage is $\geq 50 \%$. The definition of a crescent is the presence of at least 2 layers of cells totally (circumferential) or partially (circumscribed) filling the Bowman's space (1). The clinicobiological presentation is rapidly progressing glomeru- lonephritis (RPGN) characterized by glomerular syndrome with a loss of kidney function over a period of weeks to months $(1,2)$. Crescentic glomerulonephritis is a diagnostic and therapeutic emergency. The prevalence of CGN consists between $2 \%$ and $10 \%$ of all nephrological disorders (3). In sub-Saharan Africa, a few studies have been done on CGN. The aim of this study was to evaluate the clinical/biological, therapeutic, and evolutionary patterns of extra-capillary glomerulonephritis and to identify factors responsible for a poor prognosis.

\section{Methods}

This was a retrospective descriptive and analytical study based on a renal biopsy registry and the medical 
records from the nephrology department of Aristide Le Dantec university hospital in Dakar. The study was conducted over a period of five years, from January 1st, 2010 to December 30th, 2015. All reports on kidney biopsies concluding on extra-capillary glomerulonephritis (ECGN) were included. Clinical/biological, etiological, and therapeutic characteristics were identified.

The evolutionary features were collected and analyzed in order to establish factors responsible for a poor renal prognosis. After comparing the clinical, biological, histological, and etiological data, patients were divided to 2 groups (A and B) to assess factors responsible for a poor renal prognosis: group A with GFR $\geq 60 \mathrm{~mL} /$ minute after 3 months of treatment and group B with persistent kidney failure (CKD). The researchers divided these patients to 2 subgroups:

- Subgroup B1: those who evolved towards End-Stage Renal Disease (ESRD)

- Subgroup B2: those with stage 3 and 4 CKD

The data were analyzed using statistical package for social sciences (SPSS) software version 18. The averages and percentages were compared using Student's t test, $\chi^{2}$ test, and Fischer's exact test, according to their conditions of applicability. Any difference of less than 0.05 was deemed statistically significant.

\section{Results}

During the study period, 750 biopsies were performed. Forty cases of crescentic glomerulonephritis were found with a prevalence of $5.33 \%$. The mean age was $33.9 \pm 16.65$ years with a female predominance ( 26 females/14 males), i.e. a male: female gender ratio of 0.53 . The mean time from first symptoms to admission in care unit was $40 \pm 29.66$ days. Upon admission, 26 (65\%) patients presented high blood pressure and $85 \%$ had renal insufficiency. Oligoanuria was present in 25 (62.5\%) patients. The mean proteinuria was $3.22 \pm 2.78 \mathrm{~g} / 24$ hour. This was associated with microscopic hematuria in $80 \%$ of cases. Thus, the most commonly encountered clinical/biological presentation was rapidly progressive glomerulonephritis (Table 1 ).

Histologically, the mean duration from admission to renal biopsy was $4.61 \pm 4.66$ days. By light microscopy, crescents were cellular in $60.5 \%$ of cases, fibro-cellular in $57.5 \%$, and fibrous in $32.5 \%$ of cases. Completely sclerotic glomeruli were found in $5.15 \%$ of cases. Immunofluorescence was performed in 11 patients; 3 showed linear deposits, 4 had granular deposits and 4 had no deposits. Concerning the associated lesions, tubular involvement was present in all patients. Tubular necrosis was seen in 20 (50\%) patients and tubular atrophy was observed in 20 (50\%) patients. Interstitial involvement was present in 33
Table 1. Baseline Clinical, Laboratory, Histological Details of the Patients

\begin{tabular}{|c|c|}
\hline Parameters & Total Patients $(n=40)$ \\
\hline Mean age & $33.9 \pm$ ans \\
\hline Male & 14 \\
\hline Female & 26 \\
\hline $\begin{array}{l}\text { Mean time from first symptoms to admission, } \\
\text { jours }\end{array}$ & $40 \pm 29.66$ \\
\hline \multicolumn{2}{|l|}{ Clinical symptoms } \\
\hline Hypertension & $26(65)$ \\
\hline Oligoanuria & $25(62.5)$ \\
\hline Macroscopic hematuria & $4(10)$ \\
\hline Cardiac manifestation & $34(85)$ \\
\hline Pulmonary manifestation & $25(62.5)$ \\
\hline Otorhinolaryngological manifestation & $4(10)$ \\
\hline Articular manifestation & $12(30)$ \\
\hline Neurological manifestation & $18(45)$ \\
\hline \multicolumn{2}{|l|}{ Laboratory tests } \\
\hline Mean proteinuria, $\mathrm{g} / 24 \mathrm{~h}$ & $3.22 \pm 2.78$ \\
\hline Microscopic hematuria & $32(80)$ \\
\hline renal insufficiency at admission & $30(75)$ \\
\hline Mean blood creatinine, mg & $61.45 \pm 50.87$ \\
\hline Cellular crescents & $24(60.5)$ \\
\hline \multicolumn{2}{|l|}{ Histological lesion } \\
\hline Fibrous crescents & $13(32.5)$ \\
\hline Tubulars lesions & $40(100)$ \\
\hline Tubular necrosis & $20(50)$ \\
\hline Tubular atrophy & $20(50)$ \\
\hline Interstitials lesions & $33(82.5)$ \\
\hline Interstitial infiltration & $25(62.5)$ \\
\hline Fibrosis & $8(20)$ \\
\hline Vascular lesions & $22(55)$ \\
\hline
\end{tabular}

(82.5\%) patients, with interstitial infiltration in 25 (62.5\%) patients and fibrosis in 8 (20\%) patients. Vascular involvement was found in $55 \%$ of patients (Table 1 ).

Lupus was the mean etiology found in 13 patients (32.5\%), associated in one case with Gougerot-Sjögren syndrome and another case with scleroderma. ANCAassociated vasculitis was present in 11 patients (27.5\%) with 4 cases of microscopic polyangiitis, 1 case of granulomatosis with polyangiitis and 1 case of polyangiitis with eosinophilia. Acute post-infectious Glomerulonephritis (GN) was found in 7 patients (17.5\%): 2 had the otorhinolaryngological pathology, one had post-endocarditis and 2 
were post-malaria cases. For the other 2 patients, the origin of the infection was not specified (Figure 1).

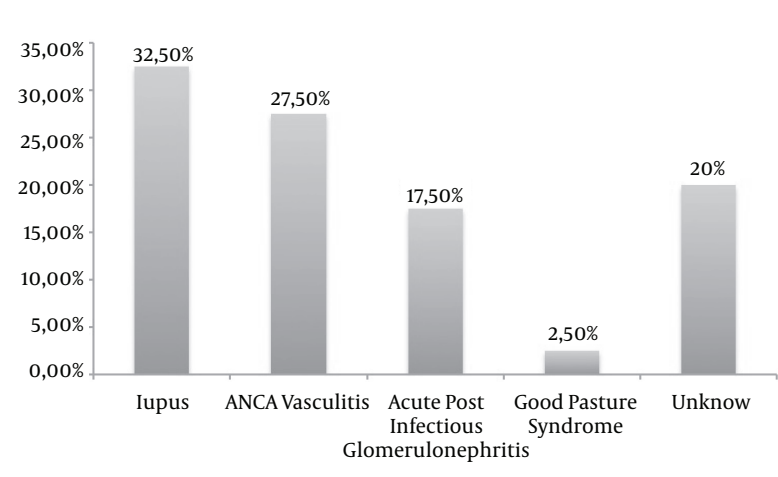

Figure 1. Etiologies of EGN

From a therapeutic point of view, hemodialysis was used in $50 \%$ of the patients. The mean number of sessions was $6.11 \pm 0.93$. Etiological treatment varied according to the cause, essentially relying on intensive immunesuppressing medication combining corticosteroids and cytotoxic drugs. Unfortunately, 10 patients could not continue treatment due to a lack of financial resources.

Regarding evolution, 7 (2.8\%) patients were lost to follow-up. Among the remaining 32 patients, 6 patients (19.27\%) had a favorable outcome with total recovery of renal function. However, in 26 patients (83.2\%), the evolution was unfavorable. Twenty-three patients (73.6\%) developed chronic renal failure and 3 (9.6\%) died during hospitalization.

Regarding renal function, poor prognostic factors found in the current study with a statistically significant correlation with an unfavorable outcome were as follows, oligoanuria on admission $(\mathrm{P}=0.028)$, high creatinine level on admission $(\mathrm{P}=0.013)$, recourse to HD $(\mathrm{P}=0.03)$, high percentage of fibro-cellular $(\mathrm{P}=0.013)$ and fibrous crescents in the renal biopsy, and a high percentage glomerular sclerosis $(\mathrm{P}=0.37)$. A high number of cellular crescents and lupus were correlated with a good renal prognosis ( $\mathrm{Ta}-$ ble 2).

\section{Discussion}

The prevalence of crescentic glomerulonephritis is around $2 \%$ to $10 \%$ of all glomerulonephritis cases in most studies: found at a rate of $7.4 \%$ in Morocco and $8.2 \%$ in South Africa (4-6). In Germany (7), as in the current study, the prevalence was 5.33\%. The annual incidence in France was $0.7 / 100,000$ (8). In an Iranian study about histopathologic patterns of adult renal disease, Mardanpour found
Table 2. Renal Prognostics Factors

\begin{tabular}{lccc}
\hline & Group B1 (n=14) & $\begin{array}{c}\text { Group A+ B2 }(\mathbf{n}= \\
\mathbf{1 6})\end{array}$ & P Value \\
\hline Gender ratio & $8 \mathrm{M} / 6 \mathrm{~F}$ & $2 \mathrm{M} / 14 \mathrm{~F}$ & 0.010 \\
\hline $\begin{array}{l}\text { Oligoanuria at } \\
\text { admission }\end{array}$ & 14 cases $(100 \%)$ & 7 cases $(43.75 \%)$ & 0.0008 \\
\hline $\begin{array}{l}\text { Mean blood } \\
\text { creatinine at } \\
\text { admission, mg/L }\end{array}$ & $91.54 \pm 46.4$ & $26.28 \pm 17.95$ & 0.0001 \\
\hline $\begin{array}{l}\text { Use of } \\
\text { hemodialysis }\end{array}$ & 13 cases $(92.86 \%)$ & 6 cases $(37.5 \%)$ & 0.0001 \\
\hline $\begin{array}{l}\text { Cellular crescents } \\
\text { Fibrocellular and } \\
\text { fibrous crescents }\end{array}$ & $66.67 \%$ & $20.83 \%$ & 0.028 \\
\hline $\begin{array}{l}\text { Scleroric } \\
\text { glomeruli }\end{array}$ & $1.17 \pm 0.98 \%$ & $83.33 \%$ & 0.013 \\
\hline
\end{tabular}

a prevalence of $4.5 \%$ of crescentic glomerulonephritis (9). The patients of the current study were young (mean age 33.9 years) with a female predominance (the male: female gender ratio was 0.53$)$. These results are similar to those reported in the literature $(6,10-13)$. In the current study, the mean time from first symptoms to admission in a care unit was $40 \pm 29.66$ days. This time limit exceeded 15 days for $70 \%$ of patients. This could be explained by the fact that patients were treated in health centers or by traditional medicine before coming to the nephrology unit. Hypertension was found in $65 \%$ of cases, associated with oligoanuria in 62.5\%. In Ozturk's series, 21 patients (51.2\%) had oliguriaanuria (14).

Upon admission, renal failure was found in $75 \%$ of patients, close to the value of $64 \%$ in the series published by Husseini (10), versus $90 \%$ in the Arrayhani series (4), and $92.4 \%$ in the series described by Zheng (6) (Table 3). However, Ozturk found that 22 patients (53.7\%) were on dialysis because of acute clinical and laboratory indications (14). Histologically, crescents were cellular in 60.5\% of cases. This was similar to Arrayhani's results, showing cellular crescents in $61.7 \%$ of patients (4). However, Husseini found that $27 \%$ of patients had cellular crescents in his series (10). Crescents were fibrous in $32.5 \%$ of cases in the current study versus $11.7 \%$ in the Husseini's series (10). The presence of fibrinoid necrotic lesions, cellularity and rupture of Bowman's capsule leads to active inflammatory lesions (2). The percentages of completely sclerotic glomeruli (5.15\%), interstitial fibrosis (20\%), and tubular atrophy (50\%) attest to the chronicity of these lesions. Lesions of different duration show a rapid evolution towards chronicity in the absence of early treatment. The importance of these tubular/interstitial lesions found in the current series could be explained by the excessive use of phy- 
totherapy in $47 \%$ of patients; this aggravated the renal disease. The severity of these histological lesions found in the current series may explain why only 6 patients (19.27\%) had a favorable outcome with total recovery of renal function.

Table 3. Clinical Etiological and Evolution Parameters in Different Studies ${ }^{\mathrm{a}}$

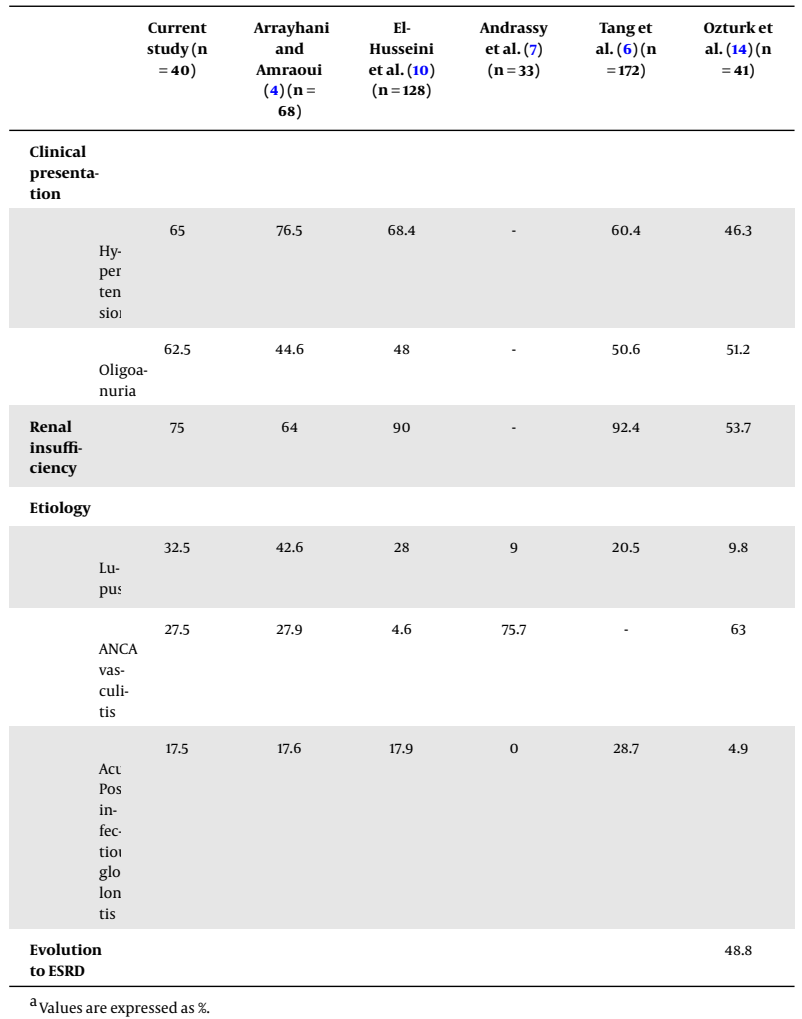

Regarding the etiologies, lupus was the first cause of ECGN found in the current series, with a percentage of $32.52 \%$. This finding is similar to that of previous studies by Arrayhani and Amraoui (4), Husseini et al. (28\%) (10), and Tang et al. (6) (20.5\%), whereas it was found only in $9 \%$ of cases in Andrassy's German series (7) and 9.8\% of cases in Ozturk's Iranian series (14). The high incidence of lupus in these African series could be explained by ethnic and racial factors. Indeed, the prevalence of lupus is more important in African-American populations than in CaucasianAmerican populations (8). According to an English study conducted in Nottingham, prevalence of lupus is 24.7/100 000 in the population as a whole against 207/100 000 for the black population of the same region (8). Vasculitis was responsible for ECGN in $75.7 \%$ of cases in the German series (7) and $63.4 \%$ in the Iranian series (14), whereas it was the cause of lesions in $27.5 \%$ of the patients of the current study, $27.9 \%$ in a Moroccan series (4) and 4.6\% in an Egyptian series (14). Infections related to ECGN were found in
17.5\% of cases for the current series, $17.6 \%$ for Arrayhani (4), 17.9\% for Husseini (10) and $28.7 \%$ for Zent (15). This etiology was found in $4.9 \%$ of cases in Ozturk series (14) and not found in Andrassy's work. The decrease in the incidence of post-infectious ECGN in Europe could be explained by improved standards of living and better medical care in Western countries compared to the developing world (Table 3 ).

On an evolutionary level, after an average follow-up of 7 months, 3 patients died. Of the remaining 30 patients, $18 \%$ had normal renal function while $53 \%$ had kidney failure. Forty-three percent (43\%) of cases in the current study developed end-stage renal disease (ESRD), as in most other series except for Andrassy's (7) where the progression was considerably better, with $55 \%$ recovering normal renal function. In Ozturk's series, twenty patients developed end-stage renal disease (14). This could be due either to ethnic factors (Caucasian versus African and Asian), etiological factors (vasculitis being the dominant etiology in this European series) or socio-economic factors. The economic level allows better access to care, availability of treatment, and comprehensive care. The ECGN secondary to lupus seemed to have a better prognosis in the current series and in the Arrayhani series (4), unlike that of Zent et al. (15) where $87 \%$ of patients had either ESRD or were deceased. Of these risk factors, 3 were common in the 4 series: oligoanuria, high creatinine level on admission and a high percentage of fibrous crescents. The current research was consistent with the series by Arrayhani and Amraoui (4), showing a high percentage of sclerotic glomeruli.

\subsection{Conclusions}

In conclusion, ECGN is a cause of rapid and irreversible renal function impairment. It was relatively common in the current study. Etiologies were dominated by lupus and infections. The relatively long period of treatment delayed diagnosis and management. This was at the root of poor recovery of renal function in the current series. The risk factors identified in the current series could improve the prognosis of ECGN in the studied population.

\section{Acknowledgments}

The authors would like to thank the International Society of Nephrology (ISN)

\section{Footnote}

Conflict of Interest: The authors declare that there was no conflict of interest regarding the publication of this paper. 


\section{References}

1. Seitz B, Esnault VLM. Crescentic glomerulonephritis. Paris: Elsevier Masson; 2009.

2. Jennette JC, Thomas DB. Crescentic glomerulonephritis. Nephrol Dial Transplant. 2001;16 Suppl 6:80-2. [PubMed: 11568252].

3. Levy M. Epidemoilogy of renal diseases. Paris: Elsevier Masson; 2008.

4. Arrayhani ME, Amraoui H. Extracapillar glomerulonephritis at Fes University Hospital : epidemiological, clinical, paraclinical and therapeutic characteristics of 68 cases. ; 2013.

5. Ampion O, Mahoungou GH, Laouad I. Rapidly Progressive Glomerulonephritis spontaneously favorable at Mohamed VI Marrakech University Hospital. Nephrol Ther. 2013;9:320-60.

6. Tang Z, Wang Z, Zhang HT, Hu WX, Zeng CH, Chen HP, et al. Clinical features and renal outcome in lupus patients with diffuse crescentic glomerulonephritis. Rheumatol Int. 2009;30(1):45-9.

7. Andrassy K, Kuster S, Waldherr R, Ritz E. Rapidly progressive glomerulonephritis: analysis of prevalence and clinical course. Nephron. 1991;59(2):206-12. [PubMed: 1956482].

8. Mahr AA. Vasculitis : Epidemiology and prognosis factors.13th Annua Meeting of the Young Nephrologists Club. Paris. .

9. Mardanpour K, Rahbar M. Histopathologic patterns of adult renal disease in Kermanshah, Iran: A 6-year review of two referral centers.
Caspian J Intern Med. 2013;4(3):717-21. [PubMed: 24009967].

10. El-Husseini AA, Sheashaa HA, Sabry AA, Moustafa FE, Sobh MA. Acute postinfectious crescentic glomerulonephritis: clinicopathologic presentation and risk factors. Int Urol Nephrol. 2005;37(3):603-9. doi: 10.1007/s11255-005-0399-6. [PubMed: 16307349].

11. Franssen CF, Stegeman CA, Oost-Kort WW, Kallenberg CG, Limburg PC, Tiebosch ATMG, et al. Determinants of renal outcome in anti-myeloperoxidase-associated necrotizing crescentic glomerulonephritis. J Am Soc Nephrol. 1998;9(10):1915-23.

12. Yu F, Tan Y, Liu G, Wang SX, Zou WZ, Zhao MH. Clinicopathological characteristics and outcomes of patients with crescentic lupus nephritis. Kidney Int. 2009;76(3):307-17. doi: 10.1038/ki.2009.136. [PubMed: 19404274].

13. Pettersson EE, Sundelin B, Heigl Z. Incidence and outcome of pauciimmune necrotizing and crescentic glomerulonephritis in adults. Clin Nephrol. 1995;43(3):141-9. [PubMed: 7774068].

14. Ozturk R, Yenigun EC, Dede F, Koc E, Turgut D, Piskinpasa SV, et al. Prognostic factors in crescentic glomerulonephritis: a single-center experience. Iran J Kidney Dis. 2015;9(1):31-8. [PubMed: 25599734].

15. Zent R, Van Zyl Smit R, Duffield M, Cassidy MJ. Crescentic nephritis at Groote Schuur Hospital, South Africa-not a benign disease. Clin Nephrol. 1994;42(1):22-9. [PubMed: 7923962]. 